\title{
Structural assessment of market capacity: client-oriented conception
}

\author{
Gregorz Mentel
}

Dr., Department of Quantitative Methods, Faculty of Management, Rzeszow University of Technology, the Repubic of Poland

\section{Galina Peresadko}

Ph.D., Chief Financial Officer, Waste Management Systems, USA

\begin{abstract}
To assess the real and potential opportunities of industrial enterprises in the market of products, a model of structural estimation of the capacity of the market for the products manufacturing has been developed. The constant and variable constituents of product market capacities are highlighted, which reflect the real business opportunities, potential queries and their purchasing power. The developed econometric model is based on the use of the multiple regression method in order to formalize the dependence of the capacity of the market of production of the industrial enterprise from the channels of influence on it, allocated using the method of the main components - price, quality, behavioral, macroeconomic, as well as with the possibility of their formalization, namely the influence of each of them on the basis of regression modeling of market data.
\end{abstract}

Keywords: market research, industry, market size, structural approach.

JEL Classification: L11, L22.

DOI: $10.21272 /$ bel.1(2).31-38.2017.

(C) The Authors, 2017. This article is published with open access at ARMG Publishing.

\section{Introduction}

One of the conditions for the successful development of industry is the efficiency of technologies, methods and tools of interaction of industrial enterprises with consumers of products. Modern marketing researches become the basis for a client-oriented conception of the development of modern industrial enterprises, the mechanism of obtaining diverse and heterogeneous data from the market, as well as the way of transforming this information into competitive advantages in the marketing of products.

The market potential of sales (market capacity) is a strategically important basis for decision making, both in the context of business entry to a new market, and the development of competitive advantages in an already existing market by finding new niches and segments for product sales.

An analysis of existing approaches to market capacity estimation suggests that they are oriented towards defining a finite quantitative parameter that characterizes the maximum sales volume and serves as one of the targets for planning the marketing policy of an enterprise. At the same time, a qualitative assessment of the market capacity, which from the standpoint of a client-oriented business strategy has a greater significance and opportunities for stimulating sales of products, remains poorly investigated. The basis of a qualitative assessment of the capacity of the company's sales market should be its structuring, which would reflect, on the one hand, the intersection of real and potential business opportunities on the market, on the other hand, the mechanisms and means of realizing these opportunities.

Structural evaluation of market capacity is the theoretical basis and peculiarities of empirical calculations.

Systematization and critical analysis of the possibilities and effectiveness of applying existing methodological approaches to the estimation of the capacity of the market of industrial enterprises allows to distinguish two groups. The first one is aimed at assessing real business opportunities in the market and focuses on the assessment of production opportunities (production method, methods based on industry growth, research index method). The second group is focused on evaluating potential sales of industrial enterprises (methods 
of basis index purchasing capacity to basis norms expenditure product, method of summation of primary, recurrent and additional sales).

None of these groups of methods allows to take into account the industrial potential of the industrial enterprise and the purchasing power of the market simultaneously. Therefore, it is expedient to develop a single generic capacity indicator based on a combination of several methods that would allow for the presence of constant and variable capacities and reflect the intersection of real and potential business opportunities on the sales market. In order to assess the real and potential market opportunities of a business, it is proposed to distinguish in the structure of the capacity of the market capacity in the industrial enterprise:

1. a permanent part that does not depend on market factors and is determined by the minimum level of social reproduction in the country and reflects the real possibilities of the business for the development of the market, that is determined by current needs and requests. For example, for machine-building enterprises, it is determined by the minimum necessary level of replacement of equipment for maintaining the appropriate level of technological equipment of the enterprise, depending on the degree of physical and moral wear of machinery / parts, the rate of scientific and technological progress in the industry, etc.; for chemical industry enterprises, it can be determined, for example, on the basis of the necessity to provide the agrarian complex of the country with the minimum required volume of mineral fertilizers, herbicides;

2. the variational part, which changes with the influence of market factors, global and national market conditions, the pace of development of scientific and technological progress, the policy of state regulation, and reflects the potential opportunities of the industrial enterprise on the product market, i.e. determined by potential (probable) queries and needs of the market.

Detection of effective mechanisms and channels of realization of real and potential opportunities of industrial enterprises in the market of sales of products requires the carrying out of scientifically substantiated market researches of market capacity with the use of economic and mathematical modeling of statistical data that reflect the current market processes in the market of products of the industrial enterprise. The developed model of structural estimation of the capacity of the industrial enterprise market is shown on Figure 1.

The first stage involves two steps, firstly, the definition of relevant indicators, that is, the basis of the quantitative characteristics of the capacity of the industrial sector market, and secondly, this specification is the choice of the form of the mathematical relation between the productive (market capacity) and the factor (relevant indicators) characteristics. Thus, on the basis of research of modern literary sources, it is proposed to highlight the following factors:

$>$ degree of market development;

$>$ the appearance of similar products and products with similar properties on the market;

$>$ elasticity of demand;

$>$ the price level;

$>$ change in macroeconomic indicators;

$>$ product quality;

$>$ efficiency on the market and advertising costs.

To evaluate the statistical significance of the parameters of the regression equation of the capacity dependence on all the considered indicators and to select only significant ones by means of Student's criterion, it is proposed to apply the method of the main components or an alternative approach.

It is suggested to carry out a quantitative estimation of the effective index of the model based on a combination of the production method and the method based on the application of the purchasing power index. This combination allows us to estimate the volume of available products, which is adjusted to the level of purchasing power of consumers in the relevant market. Formalizing this stage is proposed by combining the production method and the method based on the purchasing power index. The choice of these approaches is conditioned by the provision that, nevertheless, the market capacity is estimated by the volume of products on which it is located, and an increase in the adequacy of the effective indicator is achieved through its additional adjustment to the level of purchasing power. Thus, both the level of production and the level of consumption are taken into account. 
Consequently, moving directly to the quantitative evaluation of the effective indicator, consider consistently the first adaptation of the production method of determining the capacity of the industrial market. Thus, the total capacity of the industrial sector market will be calculated according to the following formula:

$$
V_{i p}+V_{i i p}-V_{e i p}+\Delta V_{i p}
$$

where $V_{i p}$ - the volume of production of industrial products for the period considered;

$V_{i i p}$ - the magnitude of the volume of import of industrial products for the period considered;

$V_{\text {eip }}$ - the magnitude of the volume of export of industrial products for the period considered;

$\Delta V_{i p}$ - the magnitude of the change in volumes of inventory of industrial products for the period considered.

In turn, the purchasing power index of the market participants of the industry sector is a complex integral indicator of the dependence on income and sales volumes and will be calculated using the following formula:

$$
I_{p p}=0.5 \cdot y_{i}+0.3 \cdot R_{i}+0.2 \cdot P_{i}
$$

where $y_{i}$ the share of income of the sector in the net (after tax) income of consumers in the market as a whole;

$R_{i}$ - share of sales volume of the sector in the total volume of sales in the market as a whole;

$P_{i}$ - the share of the population of the sector in the total number of consumers, which has a solvent demand in the industrial market as a whole.

Thus, the general formula for determining the capacity of the industrial sector market will take the following form:

$$
E_{i m}=\left(V_{i p}+V_{i i p}-V_{e i p}+\Delta V_{i p}\right) \cdot I_{p p}
$$

where $E_{i m}$ - capacity of the market of industrial sectors;

$I_{p p}$ - index of purchasing power of the market of industrial sectors.

At the second stage of the simulation, the formalization of the determination of the influence of the selected indicators of industrial enterprises' markets is carried out. The classical approach to the estimation of the demand elasticity index involves the calculation of the relative change in one economic indicator (the level of demand in the market of industries) for the relative change of another indicator (time factor), which can be written mathematically as follows:

$$
S=\frac{\Delta S / S}{\Delta t / t}
$$

where $\Delta S-$ change in the level of demand in the market of industry for the period $t$;

$\Delta S / S$ - the rate of change in the level of demand in the industrial market for the period $t$;

$\Delta t$ - the change in the growth rate of the time factor;

$\Delta t / t$ - the speed of change of time factor.

Calculating the price level in the market for industries, authors proposed using Markov chains. In particular, the dynamics of changes in prices for products in the market of industrial sectors is reasonable to calculate based on the transformation of the regression model of discrete Markov chain. The advantage of using the proposed toolkit is the possibility of quantitative description of the dynamics of the developed system on the basis of the probability theory apparatus considering the possible states of the system, as well as the use of the model of autoregressive type and model with distributed lag. The basis for constructing the proposed 
model is the matrix of probabilities of transition of a system from one state to another, that is, changes in the level of prices in the market of industries. The construction of the matrix of transitions is proposed on the basis of the following system of equations:

$$
\left\{\begin{array}{l}
P=\mu_{0}+\mu_{1} \cdot t+\varepsilon_{t} \\
\Delta P_{t}=\mu_{2}+\mu_{3} \cdot t+\varepsilon_{t} \\
P=\mu_{4}+\mu_{5} \cdot \Delta t+\varepsilon_{t} \\
\frac{\Delta P_{t}}{P}=\mu_{6}+\mu_{7} \cdot \Delta t+\varepsilon_{t} \\
P_{t}=\mu_{8}+\mu_{9} \cdot t+\mu_{10} \cdot P_{t-1}+\varepsilon_{t} \\
P_{t}=\mu_{11}+\mu_{12} \cdot t+\mu_{13} \cdot(t-1)+\varepsilon_{t}
\end{array}\right.
$$

where $P$ - the level of prices in the industry;

$\mu_{0}$ - constant, the value of the average level of prices for products in the industrial market in the case of time factor unchanged;

$\mu_{1}$ - constant, the value of changes in the level of prices in the industrial market in the change of time factor per unit of measurement;

$\varepsilon_{t}-$ accidental deviation of the actual and theoretical levels of prices in the market of industries;

$\Delta P_{t}$ - change in the level of prices in the industrial market for the period $t$

$\mu_{2}$ - constant, the magnitude of the average level of change in prices for products in the industrial market in the case of time factor unchanged;

$\mu_{3}$ - the constant, the magnitude of the change in the price level in the industry of the industry with a change in the growth rate of the time factor by one percent;

$\Delta t$ - change in the growth rate of the time factor;

$\frac{\Delta P_{t}}{P}$-rate of change in the level of prices in the industrial market for the period $t$;

$\mu_{6}$ - constant, mean value of the rate of change in prices for products in the industrial market in the case of time factor unchanged;

$\mu_{7}$ - constant, the magnitude of the variation in the rate of change in the level of prices in the industrial market in the change of the growth rate of the time factor by $1 \%$;

$P_{t}, P_{t-1}-$ the level of prices in the market of industrial sectors at time $t$ and the time before it;

$\mu_{8}$ - constant, the average level of prices for products in the industrial market in the case of the time factor unchanged and the price level in the previous period;

$\mu_{9}, \mu_{12}$ - constant, the magnitude of the change in the level of prices in the industrial market at the time $t$ when the time factor for the unit of measurement is changed;

$\mu_{10}$ - constant, the magnitude of the change in the price level in the industry with a change in the price level of the previous period of time by $1 \%$; 
$\mu_{11}$ - constant, the magnitude of the change in the price level at the time $t$ in the market of the industries with the constant of the factor of time in the current and the previous time period;

$\mu_{13}$ - the constant, the magnitude of the change in the level of prices in the industrial market at the time $t$ when the time factor in the previous to the considered moment per unit of measurement is changed.

The formalization of the quantitative assessment of changes in macroeconomic indicators is based on the use of the following factors: the ratio of internal and external debt to GDP, current account balance to GDP, direct investment in GDP, exports to imports, the state budget deficit to GDP, the volume of gold and foreign currency reserves to GDP, as well the rate of growth of GDP per capita, the rate of inflation, the rate of growth of industrial production and the rate of growth of the exchange rate of hryvnia to the dollar. The above list of indicators, in our opinion, reflects the main transformational changes taking place in the country at the macro level, covering the results of state regulation within the fiscal, tax, currency, investment, debt and monetary policy, and, as a consequence, affect the market of industries.

The estimation of changes in macroeconomic indicators is proposed to be carried out on the basis of the application of regression analysis, which corresponds to the chosen concept of economic and mathematical modeling of proposed scientific and methodological approach to assess the capacity of the industrial market, which mathematically can be formalized as follows:

$I_{\text {icip }}=0.5 * y_{i}+0.3 * R_{i}+0.2 * P_{i}$

where $M$ - changes in macroeconomic indicators (the ratio of domestic and foreign debt to GDP, current account surplus to GDP, direct investment in GDP, exports to imports, the deficit of the state budget to GDP, the volume of gold and foreign currency reserves to GDP, as well as the rate of GDP growth per capita, the pace of inflation, the rate of growth of industrial production and the rate of growth of the exchange rate of hryvnia to the dollar);

$\beta_{0}$ - constant, the average level of change in the capacity of the industrial sector market under the influence of the variation of macroeconomic indicators for the period considered in the case of acceptance of the factors of influence of zero values;

$\beta_{i}-$ constant value changes in the volume market size industries and increasing the value of the first macroeconomic indicator at $1 \%$;

$X_{i}$ - the value of $i$-th macroeconomic indicators.

Quantitative evaluation of the last factor attributes - quality products is offered to hold based on Koyck model with infinite lag. The need for this approach is due to the presence delay (some lag) between quantitative assessment of the quality of products on the market industries at the moment and the real value of the variable. The requirements model allows us to formalize the Koyck model by introducing lagged variables on the right of the corresponding regression equation.

In addition, product quality is not aquantitative characteristic, that is why one of its analytical approach to assessment with a fairly high degree of accuracy (researchers choose the number of lagged variables entered into the model) is the formalization of the bunk using the model. Along with these benefits application of the model should be emphasized that the quality of products serving the dynamic characteristic that is constantly changing over time. That is why there is a need to establish quantitative values depending on the studied parameters of the time factor, which allows us to build the Koyck model. Thus, the mathematical formalization of this stage can be represented as follows:

$E_{m}=\alpha_{0}+\alpha_{1} \cdot S+\alpha_{2} \cdot P+\alpha_{3} \cdot M+\alpha_{4} \cdot Q$

where $Q$ - quantification of the quality of products on the market industries;

$q_{0}$ - constant, the value of the average level of quantitative assessment of the quality of products on the market; 
$q_{1}$ - constant changes in value of quantitative assessment of the quality of products on the market of industries by changing the time factor per unit of measurement;

$q_{2}$ - constant changes in value of quantitative assessment of the quality of products on the market of industries by changing the time factor since the previous unit of measurement;

$\gamma_{t}$ - random deviation of actual and theoretical levels of product quality quantitative assessment of market sectors.

The final calculations within this phase is to identify the parameters of the key factors of the market capacity of companies in the industry by least squares given above derived time series. Thus, the results of the corresponding calculations, namely quantitative assessment of left regression equation - effective signs and factors right side of this equation is obtained array of statistics - column values regressors and regressants. These data serve basis for determining the regression equation, i.e. quantitative assessment of its parameters. The need to determine the parameters due to the fact that they do not act in time variables and constants to be determined to record the integral parameter estimates market size industries. So, given the results of the previous stages of research and methodical approach, it is proposed to introduce the equation of the following formula:

$\left(V+V_{i}-V_{e}+\Delta V\right) \cdot I_{c p}=\alpha_{0}+\alpha_{1} \cdot S+\alpha_{2} \cdot P+\alpha_{3} \cdot M+\alpha_{4} \cdot Q$

The final third stage of modeling is to determine the integral index of quantitative assessment of market capacity of companies in the industry. The following conversion can be consistently carried out considering the formalization of factors in mathematical formula:

1. taking into account the market demand elasticity of industry:

$E_{p n}=\alpha_{0}+\alpha_{1} \cdot \frac{\Delta S / S}{\Delta t / t}+\alpha_{2} \cdot P+\alpha_{3} \cdot M+\alpha_{4} \cdot Q$

2. considering the level of prices in the market industry through the use of discrete Markov chain:

$$
\begin{aligned}
& E_{p n}=\alpha_{0}+\alpha_{1} \cdot \frac{\Delta S / S}{\Delta t / t}+\alpha_{2} \cdot P+\alpha_{3} \cdot M+\alpha_{4} \cdot Q \\
& \left\{\begin{array}{l}
P=\mu_{0}+\mu_{1} \cdot t+\varepsilon_{t} \\
\Delta P_{t}=\mu_{2}+\mu_{3} \cdot t+\varepsilon_{t} \\
P=\mu_{4}+\mu_{5} \cdot \Delta t+\varepsilon_{t} \\
\frac{\Delta P_{t}}{P}=\mu_{6}+\mu_{7} \cdot \Delta t+\varepsilon_{t} \\
P_{t}=\mu_{8}+\mu_{9} \cdot t+\mu_{10} \cdot P_{t-1}+\varepsilon_{t} \\
P_{t}=\mu_{11}+\mu_{12} \cdot t+\mu_{13} \cdot(t-1)+\varepsilon_{t}
\end{array}\right.
\end{aligned}
$$

3. including the quantitative assessment of changes in macroeconomic indicators based on the use of regression analysis:

$$
\begin{aligned}
& E_{p n}=\alpha_{0}+\alpha_{1} \cdot \frac{\Delta S / S}{\Delta t / t}+\alpha_{2} \cdot\left(\beta_{0}+\sum_{i=1}^{n} \beta_{i} \cdot X_{i}\right)+\alpha_{3} \cdot M+\alpha_{4} \cdot Q \\
& \left\{\begin{array}{l}
P=\mu_{0}+\mu_{1} \cdot t+\varepsilon_{t} \\
\Delta P_{t}=\mu_{2}+\mu_{3} \cdot t+\varepsilon_{t} \\
P=\mu_{4}+\mu_{5} \cdot \Delta t+\varepsilon_{t} \\
\frac{\Delta P_{t}}{P}=\mu_{6}+\mu_{7} \cdot \Delta t+\varepsilon_{t} \\
P_{t}=\mu_{8}+\mu_{9} \cdot t+\mu_{10} \cdot P_{t-1}+\varepsilon_{t} \\
P_{t}=\mu_{11}+\mu_{12} \cdot t+\mu_{13} \cdot(t-1)+\varepsilon_{t}
\end{array}\right.
\end{aligned}
$$

4. taking into account the quantitative assessment of the quality of products on the market industry by constructing a model of Koyck: 


$$
\begin{aligned}
& E_{p n}=\alpha_{0}+\alpha_{1} \cdot \frac{\Delta S / S}{\Delta t / t}+\alpha_{2} \cdot P+\alpha_{3} \cdot\left(\beta_{0}+\sum_{i=1}^{n} \beta_{i} \cdot X_{i}\right)+ \\
& +\alpha_{4} \cdot\left(q_{0}+q_{1} \cdot t+q_{2} \cdot(t-1)+q_{3} \cdot(t-2)+\ldots+\gamma_{t}\right) \\
& \left\{\begin{array}{l}
P=\mu_{0}+\mu_{1} \cdot t+\varepsilon_{t} \\
\Delta P_{t}=\mu_{2}+\mu_{3} \cdot t+\varepsilon_{t} \\
P=\mu_{4}+\mu_{5} \cdot \Delta t+\varepsilon_{t} \\
\frac{\Delta P_{t}}{P}=\mu_{6}+\mu_{7} \cdot \Delta t+\varepsilon_{t} \\
P_{t}=\mu_{8}+\mu_{9} \cdot t+\mu_{10} \cdot P_{t-1}+\varepsilon_{t} \\
P_{t}=\mu_{11}+\mu_{12} \cdot t+\mu_{13} \cdot(t-1)+\varepsilon_{t}
\end{array}\right.
\end{aligned}
$$

\section{Conclusions}

Thus, summing up the justification for the model, we note that the methodology of structural estimation of the market capacity of industrial enterprises was developed for the first time on the basis of its permanent component accounting (reflects the real business opportunities for market development) and the variability (determined by potential inquiries and market needs) in order to identify the intersection of real and potential opportunities of the enterprise in the sales market and the definition of mechanisms and means for realizing these opportunities. The tool of evaluation, which involves the use of a linear multiple regression and allow for the dynamic changes in market capacity of production of industrial enterprises and the stochastic nature of the factors, causes it. Significant advantages of the proposed approach is the ability to take into account the pricing behavior and the quality of goods, works and services in the industries by applying the Markov chains and the Koyck model. In addition, the advantages include the prospect of considering the dynamic essence of market capacity of industries and stochastic nature of factors affecting it based on the application of methods of economic and mathematical modeling. In addition to this, rightly noted that the formalization of a theoretical model evaluating market size industries allows us to identify the scientific achievements of the market size of each industry, and its slight transformation and adaptation to the conditions of the study significantly expands the scope of dynamic evaluation of categories.

\section{References}

1. Armstrong, J.S. (2001). Selecting Forecasting Methods. In Principles of Forecasting: A Handbook for Researchers and Practitioners. Kluwer Academic Publishers, 19 p.

2. Armstrong, J.S., Brodie, R.J. (1999). Forecasting for Marketing. In Quantitative Methods in Marketing, Second Edition. London: International Thompson Business Press, pp. 92-119.

3. Belk, R.W., Miller, D. (1995). Studies in the new consumer behaviour. Acknowledging Consumption. A Review of New Studies. London and New York: Routledge.

4. Belulaj, Arbnor, Celion, Fredrik (2011). Industrial Buyer Behavior. A Study of the Industrial Buying Behavior in Life Science Organizations When Faced With a Radical Innovation. Uppsala Universitet, 49 p.

5. Chendler, A.D. (1962). Strategy and Structure: A Chapter in History of Industrial Enterprises. Cambridge: MIT Press, $724 \mathrm{p}$.

6. Chisnall, P. (1992). The essence of marketing research. New York: Prentice Hall, 211 p.

7. Dachler, Peter H. (1997). Qualitative Methods in Organizational Research: A Practical Guide. Organizational Studies, pp. 709-724.

8. Eker, S., Slinger, J., Yucel, G. (2011). Investigating an automated method for the sensitivity analysis of functions. Proceedings of the 29th International Conference of the System Dynamics Society, July 24-28, 2011, Washington, DC., 22 p.

9. McGregor, D. (1957). The Human Side of Enterprise. Proceeding of the First Anniversary Convocation of the School of Industrial Management. Cambridge, Mass.: Massachusetts Institute of Technology, April 9, 423 p.

10. Sheth, J.N. (1973). A Model of Industrial Buyer Behavior. Journal of Marketing, 37 (October), 50-56.

11. Zairi, M. (1992). Benchmarking for Best Practice. Oxford: Butterworth-Heinemann. 512 p. 


\section{Appendix}

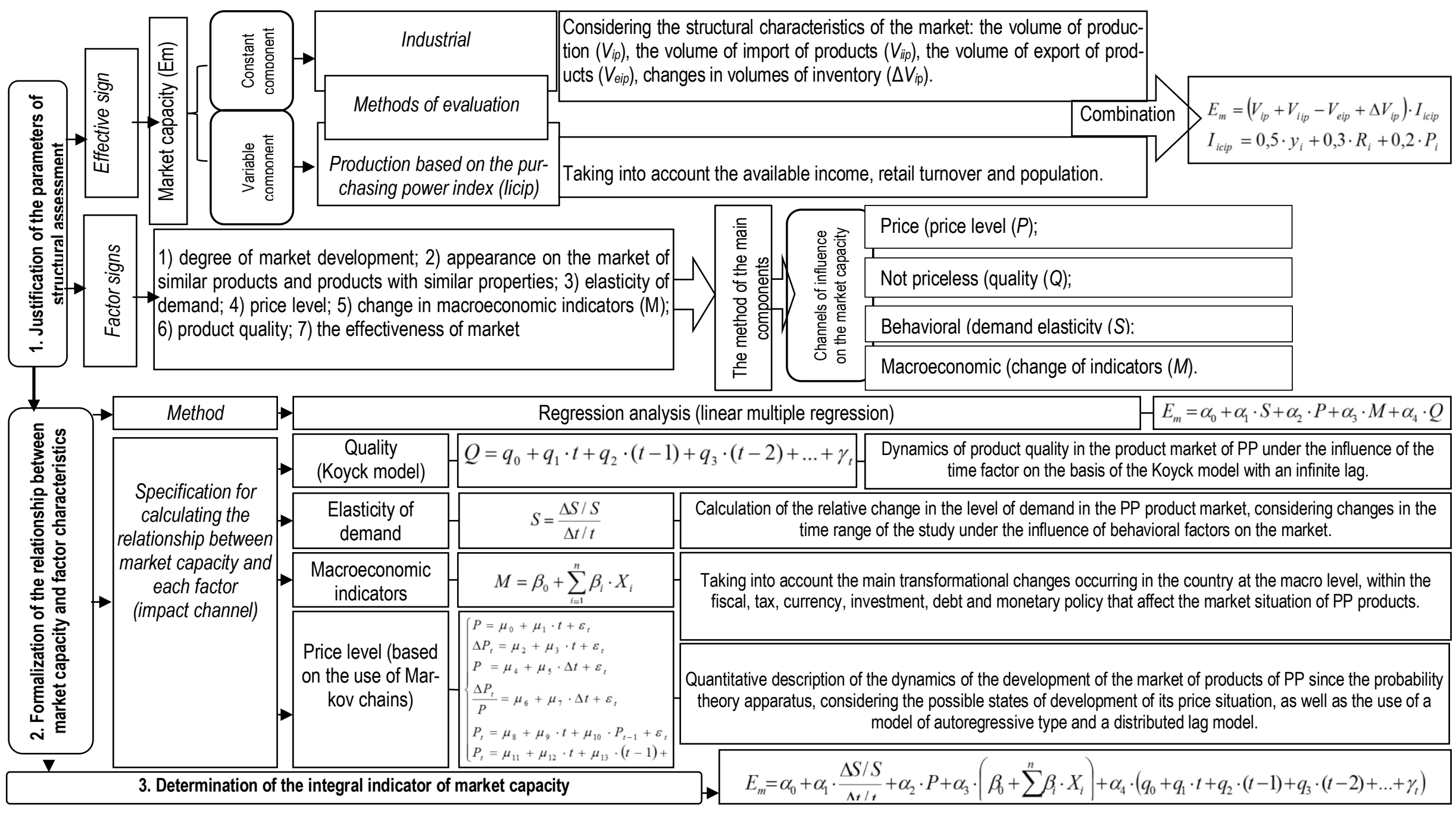

Figure 1. Model of structural estimation of the capacity of the business product market

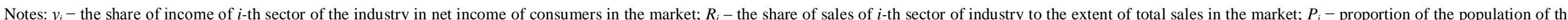

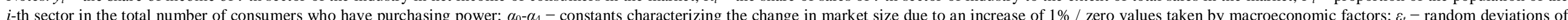
actual and theoretical levels of market prices; $\Delta P_{t}-$ change in market prices over time $t ; \Delta S / S-$ the rate of change of market demand for the period $t ; \Delta t-$ change in the time range of research. 